\title{
Developing Research Priorities for Prediction and Prevention of Preterm Birth
}

\author{
William A. Agger, MD; Charles W. Schauberger, MD, MS; James K. Burmester, PhD; and \\ Sanjay K. Shukla, PhD
}

$\mathrm{O}$ ften a devastating event for expectant parents, spontaneous preterm birth (SPTB) is the leading cause of infant morbidity and mortality in the industrialized world. ${ }^{1}$ SPTB may follow premature rupture of the chorioamniotic membranes with early (prior to 37 weeks of gestation) delivery of the child. These neonates may have low birth weight, sometimes associated intracranial bleeding, necrotizing enterocolitis, bronchopulmonary dysplasia, and retinopathy of prematurity. According to a 2007 Institute of Medicine report, such SPTB neonatal complications account for more than $\$ 26$ billion per year in the United States. ${ }^{2}$ Since that publication, changes in medical care have occurred that include policy shifts to prevent SPTB, such as using single embryo transfer during assisted reproductive technology in women younger than 35 years, which have led to a slightly reduced incidence of SPTB in the United States. ${ }^{3}$

Further reduction in the rate of SPTB will require substantial research aimed at understanding the factors contributing to SPTB. Risk factors contributing to SPTB include ethnicity, low socioeconomic status, poor nutrition, smoking, alcohol use, and substance abuse. Maternal risk factors of significance include maternal and fetal genetics, prior preterm birth, short interpregnancy interval, multiple gestation, diabetes, being over- or under-weight, short cervical length, and periodontal disease. ${ }^{4}$ The effects of the complex interactions of these risks on SPTB over the entire pregnancy must be explored.

One potentially modifiable factor in SPTB may be found in the vaginal microbiome. Microbial infections, such as bacterial vaginosis, have one of the strongest associations with SPTB. ${ }^{5}$ Bacterial vaginosis is associated with the development of chorioamnionitis, an intra-amniotic infection found in placentas of $40 \%$ of all preterm births, and is particularly prevalent when births occur before 35 weeks of gestation. Although multiple studies demonstrate that

Corresponding Author: William A. Agger, MD, Infectious Disease Section, Mail Stop C04-00I, Gundersen Health System, I 900 South Avenue, La Crosse,WI 5460I, Telephone: (608) 775-2I40, Fax: (608) 775-5542, Email: waagger@gundersenhealth.org individual infectious agents and a community of infectious agents could contribute to SPTB, it remains unclear how these changes in microbiota cause SPTB. ${ }^{6}$ Sequential changes in the microbiota during the pregnancy likely are important in either initiating inflammation or suppressing protective factors, resulting in rupture of membranes; however, our understanding of the role of microbiota in SPTB is rather limited. Therefore, research to characterize the entire microbiome present in vaginal and placental tissues is important and may lead to a better understanding of the role of bacteria in SPTB. ${ }^{5,7}$ If one or more new pathogenic bacteria or relative admixtures of new or changing microbial vaginal flora can be identified, new methods might be developed to prevent the early inflammatory triggers of SPTB by vaginal microbes.

As in other health conditions, patient education can help in reducing disease incidence. To decrease the incidence of SPTB, we should redouble efforts to educate mothers about preventive methods that have been shown to be effective. For instance, studies demonstrate that using health care services before, during, and after pregnancy has a positive effect on outcomes. ${ }^{9}$ For example, lack of treatment for bacteriuria, both symptomatic and asymptomatic, is associated with SPTB. Continued identification of the causes of SPTB may allow further augmentation of effective social education programs. These programs have been successful in reducing the rate of SPTB through interventions that include reduction or discontinuation of smoking, alcohol, and illicit drug use. Strategies to reduce the teenage birth rate have also reduced the rate of SPTB, but at the other end of the spectrum, delays in childbearing can increase the rate of SPTB, making this a difficult choice for women.

Surgical and medical methods to reduce the incidence and severity of preterm birth include cervical cerclage and

Keywords: Premature birth; Inflammation; Risk factors; Vaginosis, Bacterial; Microbiota

Received: May 17, 2016
Revised: August II, 2016
Accepted: August 22, 2016
doi:10.3121/cmr.2016.1330

doi: $10.3121 / \mathrm{cmr} .201$ 


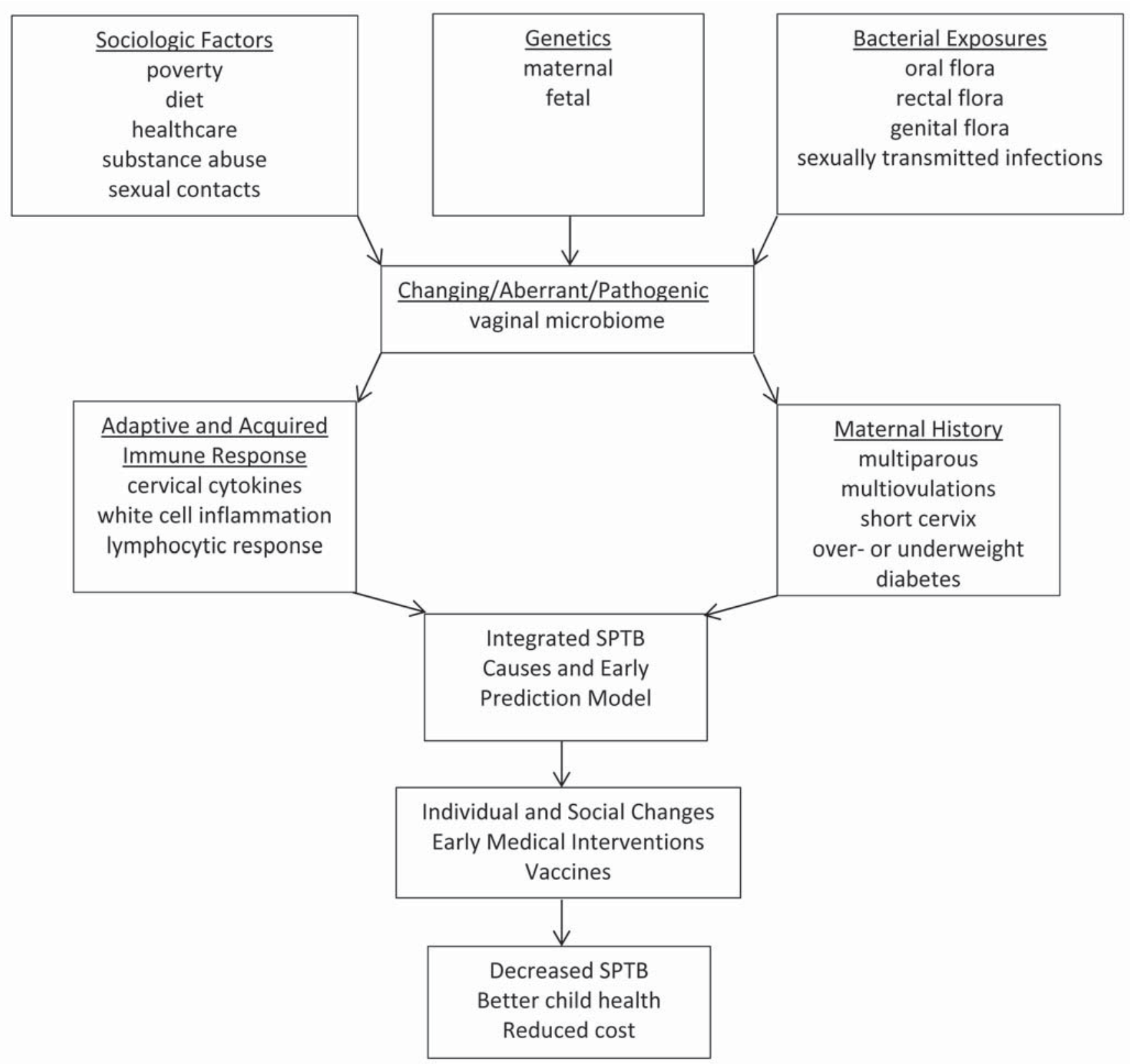

Figure 1. Selected areas of intervention for reducing the morbidity and mortality of spontaneous preterm birth. SPTB indicates spontaneous preterm birth.

tocolytic treatment. Successful use of these interventions requires the accurate prediction and assessment of mothers at high risk for SPTB. In addition to measurements of cervical length, several molecular tests that help predict SPTB have been developed, although none are sufficiently sensitive or specific to be commonly used in pregnancies. Such tests include fetal fibronectin, proteases, and interleukins (IL1- $\beta$, IL6, and IL8). ${ }^{10}$ Other tests that include analysis of inflammation by bloodstream markers, such as sensitive C-reactive protein, are now available but have not been fully studied.
It is apparent that substantial advances are needed in our understanding of the molecular changes in cytokines and hormones that occur in SPTB to more accurately predict which women will have SPTB. These advances may provide new targets for prevention and treatment prior to SPTB. Because abnormalities in the vaginal microbiota are associated with preterm birth, public education of pregnant mothers to avoid certain behaviors and/or environmental sources of microbes may help to reduce the incidence of SPTB. Furthermore, the identification of new infectious agents, including otherwise low-grade, opportunistic pathogens, could lead to development of new antibiotic therapies or vaccines. 
Development of an integrated model that predicts SPTB (Figure 1) will likely include genetic factors from the mother and the fetus. Some of the variants appear to cause the onset of SPTB, whereas some appear to delay it. Increasing our understanding and ability to prevent or delay SPTB would be of great societal benefit. Identification of genetic variants that associate with SPTB is ongoing, and an international preterm labor genetic consortium that includes participants from multiple ethnic/racial groups has been formed. ${ }^{11}$ Owing to the large number and complexity of the factors that affect SPTB, such a multidisciplinary, multiregional approach will be required.

Finding new therapies to prevent or reduce the incidence of SPTB will require certain considerations. New therapies must delay the onset of delivery without adversely affecting either the developing child or the mother. Because most women will deliver at or near term, targeting non-symptomatic women will increase risk to a large number of women who otherwise would have a near- or full-term pregnancy. In such pregnancies, therapies designed to stop or slow labor once it has started may have limited utility because they may make only small changes in the total length of the pregnancy. However, any education, vaccinations, testing, and treatments that can decrease SPTB before 35 weeks of gestation could have a markedly positive effect on health care - not only in America, but around the world. ${ }^{12}$

\section{References}

1. McCabe ERB, Carrino GE, Russell RB, Howse JL. Fighting for the next generation: US prematurity in 2030. Pediatrics. 2014;134:1193-1199.

2. Institute of Medicine (US) Committee on Understanding Premature Birth and Assuring Healthy Outcomes. Behrman RE, Butler AS, eds. Preterm birth: Causes, consequences, and prevention. Washington, DC: National Academies Press; 2007. http://www.ncbi.nlm.nih.gov/books/NBK11362/

3. Schoen CN, Tabbah S, Iams JD, Caughey AB, Berghella V. Why the United States preterm birth rate is declining. Am J Obstet Gynecol. 2015;213:175-180.

4. Blencowe H, Cousens S, Chou D, Oestergaard M, Say L, Moller A-B, Kinney M, Lawn J; Born Too Soon Preterm Birth Action Group. Born too soon: the global epidemiology of 15 million preterm births. Reprod Health. 2013;10 Suppl 1:S2.

5. DiGiulio DB, Callahan BJ, McMurdie PJ, Costello EK, Lyell DJ, Robaczewska A, Sun CL, Goltsman DS, Wong RJ, Shaw G, Stevenson DK, Holmes SP, Relman DA. Temporal and spatial variation of the human microbiota during pregnancy. Proc Natl Acad Sci U S A. 2015;112:11060-11065.

6. Payne MS, Bayatibojakhi S. Exploring preterm birth as a polymicrobial disease: an overview of the uterine microbiome. Front Immunol. 2014;5:595.

7. MacIntyre DA, Chandiramani M, Lee YS, Kindinger L, Smith A, Angelopoulos N, Lehne B, Arulkumaran S, Brown R, Teoh TG, Holmes E, Nicoholson JK, Marchesi JR, Bennett $\mathrm{PR}$. The vaginal microbiome during pregnancy and the postpartum period in a European population. Sci Rep. 2015;5:8988.
8. Lamont RF, Sobel JD, Akins RA, Hassan SS, Chaiworapongsa T, Kusanovic JP, Romero R. The vaginal microbiome: new information about genital tract flora using molecular based techniques. BJOG. 2011;118:533-549.

9. Gee RE, Johnson KA. Louisiana Birth Outcomes Initiative: improving birth outcomes with interventions before, during, and after pregnancy. J La State Med Soc. 2012;164:6-9.

10. Romero R, Dey SK, Fisher SJ. Preterm labor: one syndrome, many causes. Science. 2014;345:760-765.

11. Pennell CE, Vadillo-Ortega F, Olson DM, Ha EH, Williams S, Frayling TM, Dolan S, Katz M, Merialdi M; Preterm Birth Genome Project (PGP) Consortium, Menon R. Preterm Birth Genome Project (PGP) -- validation of resources for preterm birth genome-wide studies. J Perinat Med. 2013;41:45-49.

12. Agger WA, Siddiqui D, Lovrich SD, Callister SM, Borgert AJ, Merkitch KW, Mason TC, Baumgardner DJ, Burmester JK, Shukla SK, Welter JD, Stewart KS, Washburn MJ, Bailey $\mathrm{HH}$. Epidemiologic factors and urogenital infections associated with preterm birth in a midwestern U.S. population. Obstet Gynecol. 2014;124:969-977.

\section{Author Affiliations}

William A. Agger, MD*ץ; Charles W. Schauberger, MD, MSt; James K. Burmester, PhD ; Sanjay K. Shukla, $\operatorname{PhD} \S$

*Infectious Disease Section, Gundersen Health System, La Crosse, Wisconsin

†Department of Medical Research, Gundersen Medical

Foundation, La Crosse, Wisconsin

IDepartment of Obstetrics \& Gynecology, Gundersen

Health System, La Crosse, Wisconsin

§Marshfield Clinic Research Foundation, Marshfield,

Wisconsin 